\title{
A Justiça Socioecológica e suas dimensões: o Acolhida na Colônia no estado de Santa Catarina, Brasil
}

\author{
Socio-Ecological Justice and its dimensions: the Acolhida na Colônia in the state of Santa \\ Catarina, Brazil
}

\author{
Andrei Stock ${ }^{1}$ \\ Luciano Felix Florit ${ }^{2}$ \\ Lucia Helena de Souza Martins ${ }^{3}$ \\ Valmor Schiochet ${ }^{4}$
}

\section{Resumo}

A Justiça Socioecológica envolve uma nova visão de mundo, contrária ao utilitarismo atual. Trata-se de uma visão onde o respeito e a dignidade devem abranger não apenas aos seres humanos, mas também os demais organismos vivos. Possui quatro dimensões: a temporal (preocupação com as gerações futuras); a territorial (dentro das diferentes escalas territoriais); social (grupos sociais vulneráveis) e a ecológica (respeito às espécies e aos indivíduos não humanos). O principal objetivo desse estudo foi analisar o projeto Acolhida na Colônia em relação às dimensões da Justiça Socioecológica. A instituição, que atua principalmente no estado de Santa Catarina no sul do Brasil, foi criada para desenvolver o agroturismo, modalidade de turismo desenvolvida no espaço rural onde agricultores familiares organizados estão dispostos a compartilhar seu modo de vida, patrimônio cultural e natural, mantendo suas atividades econômicas, oferecendo produtos e serviços de qualidade, valorizando e respeitando o ambiente e a cultura local e proporcionando bem-estar aos envolvidos. A investigação teve uma abordagem qualitativa buscando a verificação da realidade estudada por meio de entrevistas semiestruturadas. Como resultados do estudo concluímos que existem ressalvas, mas o projeto Acolhida na Colônia reúne esforços para adequar-se as dimensões da Justiça Sócio- Ecológica.

Palavras-chave: Agricultura familiar. Mudanças. Desenvolvimento. Justiça Socioecológica.

\begin{abstract}
Socio-Ecological Justice involves a new world point of view, contrary to current utilitarianism. It is a vision where respect and dignity must encompass not only human beings, but also other living organisms. It has four dimensions: temporal (concerns for future generations); territorial (within the different territorial scales); social (vulnerable social groups) and ecological (respect for species and non-human individuals). The main objective of this study was to analyze the Project Acolhida na Colônia in relation to the dimensions of the Socio-Ecological Justice. The institution, which operates mainly in the state of Santa Catarina in southern Brazil, was created to develop agrotourism, a form of tourism developed in rural areas where organized family farmers are willing to share their way of life, cultural and natural heritage, maintaining their economic activities, offering quality products and services, valuing and respecting the local environment and culture and providing well-being to those involved. The research had a qualitative approach seeking the verification of the reality studied through semi-structured interviews. As a result of the study, we conclude that there are caveats, but the project Acolhida na Colônia gathers effort to fit the dimensions of Socio-Ecological Justice.

Keywords: Family farming. Changes. Development. Socio-Ecological Justice.

\footnotetext{
1 Doutorando em Desenvolvimento Regional pela Universidade Regional de Blumenau (FURB). E-mail: andreistock@hotmail.com

${ }^{2}$ Professor do Programa de Pós-Graduação em Desenvolvimento Regional (FURB). E-mail: lucianoflorit@gmail.com

${ }^{3}$ Doutoranda em Desenvolvimento Regional (FURB). E-mail: lhsmartins24@ gmail.com

4 Professor do Programa de Pós-Graduação em Desenvolvimento Regional (FURB). E-mail: valmorschiochet@gmail.com
} 


\section{Introdução}

Garantir condições de qualidade de vida às gerações futuras tanto de seres humanos quanto não-humanos passa pela mudança de paradigmas. É cada vez mais difundido o conhecimento acerca da degradação ambiental e suas consequências - ainda que haja divergências do quão destrutivo tem sido o comportamento do ser humano em relação à Terra. Assegurar o bem-estar das próximas gerações e da própria natureza está em consonância com as práticas pregadas pela Justiça Socioecológica, que surge como alternativa ao status quo. As dimensões temporal, social, territorial e ecológica procuram aportar todos os aspectos fundamentais para que a vida - em todas as formas possa se perpetuar sem prejuízos. Portanto, a Justiça Socioecológica coloca-se como contraponto ao modelo capitalista, que sobrepõe o crescimento econômico em detrimento dos seres - humanos ou não - e da própria natureza. Não são poucas as evidências de que a visão economicista está nos empurrando ao abismo principalmente quando verificamos as alterações climáticas ocorridas nos últimos anos e que mantem um viés claro de piora (BBC, 2015).

A partir dos conceitos trazidos pela Justiça Socioecológica torna-se evidente a necessidade de mudança desde o nível micro. Com base neste pensamento, este estudo parte da análise do projeto Acolhida na Colônia tendo como objetivo compreender se o projeto está em consonância com os preceitos da Justiça Socioecológica, apresentando uma alternativa ao modelo tradicional de desenvolvimento às pequenas propriedades agrícolas familiares.

O projeto Acolhida na Colônia conta com 73 propriedades familiares, distribuídas em 18 municípios catarinenses. Compreende as regiões das Encostas da Serra Geral (Anitápolis, Gravatal, Imbituba, Rancho Queimado, Santa Rosa de Lima, São Bonifácio), Ibirama (Apiúna, Presidente Getúlio, Presidente Nereu, Vitor Meirelles e Witmarsum), Ituporanga (Aurora e Atalanta), Vale dos Imigrantes (Rio do Sul, Agrolândia, Agronômica) e Serra Catarinense (São Joaquim e Urubici) (ACOLHIDA, 2015).

Para saber da realidade do Acolhida na Colônia foi necessário ter contato direto com os participantes, por isso, foi necessário fazer o recorte de amostragem. Neste caso, optou-se pela regional de Ituporanga, que possui dez propriedades fazendo parte do projeto. Ao todo, seis propriedades foram visitadas entre os meses de outubro e dezembro de 2015, todas localizadas nos municípios de Aurora e Atalanta. A investigação teve uma abordagem qualitativa buscando a verificação da realidade estudada por meio de coleta de dados sem medição numérica. $\mathrm{O}$ método qualitativo usa, habitualmente, descrições e observações, requerendo coleta de dados, abertura, flexibilidade e capacidade de observação e de interação com os atores sociais relacionados ao estudo (SAMPIERI et al, 2006, p. 5). Sendo assim, as técnicas utilizadas em campo nesse processo de 
investigação foram a observação e a entrevista semiestruturada. Nela, o entrevistador baseia-se num questionário pré-elaborado, mas tem a liberdade de introduzir mais perguntas no decorrer da conversa, seja para obter informações precisas ou dados sobre outros temas abordados (SAMPIERI et al., 2006).

Por meio das perguntas previamente elaboradas buscou-se identificar variáveis econômicas, sociais, espaciais, culturais e ecológicas. Aprofundando, assim, a conexão entre as experiências dos entrevistados dentro das dimensões da Justiça Socioecológica, que são: a temporal (preocupação com as gerações futuras); a territorial (relação entre diferentes escalas territoriais), a social (consideração de grupos sociais vulneráveis) e a ecológica (respeito a espécies e indivíduos não humanos). A intenção foi verificar se a Acolhida na Colônia caminha ou não em consonância com a Justiça SócioEcológica. Tendo em mente os deveres éticos da pesquisa e do pesquisador, sobretudo o respeito ao ser humano, optou-se por preservar a identidade dos entrevistados. A intenção é evitar a exposição das diferentes abordagens e opiniões dos proprietários rurais sobre os assuntos tratados. Para fins metodológicos, identificou-se as propriedades com nomes de árvores da mata Atlântica, sendo estas "Ipê”, “Imbuia”, "Ingá”, "Manacá”, “Cedro" e "Canela”.

$\mathrm{O}$ artigo está dividido em três capítulos, além desta introdução e das considerações finais. O primeiro capitulo traz uma explanação sobre a Justiça Socioecológica e as suas dimensões. O segundo capítulo apresenta breve histórico sobre a experiência francesa do Accueil Paysan, o projeto Acolhida na Colônia e sua implantação em Santa Catarina. Por fim, o terceiro capitulo traz os resultados da pesquisa de campo feitas nas propriedades atuantes na Acolhida na Colônia na regional Ituporanga e sua contextualização junto às dimensões da Justiça Socioecológica.

\section{A Justiça Socioecológica e suas dimensões}

A Justiça Socioecológica envolve uma nova visão de mundo contrária ao utilitarismo atual. Prega que o respeito e a dignidade devem ser estendidos não apenas às pessoas, mas a todos os organismos. A Justiça Socioecológica tem clara percepção de que a natureza e os demais seres não existem para satisfazer as necessidades dos humanos, mas que estamos todos interligados. Conta com quatro dimensões: temporal, territorial, social e ecológica (adaptado de KOPNINA, 2014).

A dimensão temporal é comumente concebida como justiça entre as gerações presentes e futuras dos seres humanos. Os conceitos temporais nos fazem refletir sobre as preocupações e as incertezas para as futuras gerações devido aos atuais padrões de crescimento e consumo (KOPNINA, 2014). Implica no equilíbrio das oportunidades e condições que possibilitem uma vida digna a todas 
as pessoas, numa mesma geração (equidade intrageracional) e entre gerações (equidade intergeracional), independente da nacionalidade, etnia, credo, gênero, filiação política, condição física, social, econômica ou cultural (ZUINDEAU, 2007). Embora esta concepção esteja aparentemente ligada ao termo desenvolvimento sustentável, que busca suprir as demandas do presente sem comprometer a capacidade das gerações futuras de responder às suas necessidades, ela nasce nos debates sobre o desenvolvimento sustentável, e avança teoricamente para uma concepção de preservação dos seres, humanos e não humanos, no tempo e no espaço.

A dimensão territorial da Justiça Socioecológica refere-se à exposição desigual dos países desenvolvidos e em desenvolvimento a riscos e benefícios ambientais, tais como as consequências das alterações climáticas. Podemos verificar estas desigualdades a partir maneira como os países do Norte, desenvolvidos, se relacionam como os países do Sul, subdesenvolvidos ou em desenvolvimento, embora possam existir desigualdades regionais no interior de um mesmo país. A dimensão territorial constitui uma abordagem de observação inclusive para entendermos melhor as questões de equidade intrageracional do ponto de vista das relações entre indivíduos ou entre as categorias sociais (ZUINDEAU, 2007).

Enquanto nações desenvolvidas evocam discursos ambientalistas, delegam a produção de bens de consumo a outros países, invariavelmente subdesenvolvidos. A conta mais pesada (poluição, desmatamento, exploração humana, etc.) fica com os mais pobres. Ao mesmo tempo em que os países desenvolvidos, muitos com pouquíssimas reservas naturais, impõe medidas de proteção ambiental às nações, que além de terem menos recursos financeiros para investimento, são comercialmente exploradas em nível internacional (ALIER, 2007).

A dimensão social refere-se à distribuição desigual dos encargos ambientais, tais como atividades perigosas e poluentes, para os grupos vulneráveis, como as minorias étnicas, agricultores familiares ou demais populações segregadas e vulneráveis (KOPNINA, 2014). A degradação ambiental gera ainda mais desigualdades sociais.

[...] A medida que se expande a escala da economia, mais resíduos são gerados, mais os sistemas naturais são comprometidos, mais se deterioram os direitos das gerações futuras, mais o conhecimento dos recursos genéticos é perdido. Alguns grupos da geração atual são privados do acesso aos recursos e serviços ambientais, e sofrem muito mais com a contaminação" (ALIER, 2007, p. 36).

A dimensão ecológica diz respeito a espécies e indivíduos não humanos. Envolve o chamado igualitarismo biosférico, refere-se à equidade entre espécies humanas e não-humanas e da valorização dos seres de outras espécies independente do seu valor instrumental para os seres humanos (BAXTER, 2005). 
Diferente de outras sociedades, nossa formação de caráter cultural e político não reconhece valores a longo prazo. Nossa formatação moral é signatária da concepção aristotélica, antropocêntrica e hierárquica, típica da racionalidade escravocrata. A concepção ética de Pitágoras nos teria levado ao domínio não-tirânico sobre outras espécies vivas, mas ela continua a ser ocultada nos ensinamentos acadêmicos. O fundamento da ética ambiental deve considerar todos os seres sencientes, incluindo os que ainda irão habitar o planeta (SINGER, 1998).

Estamos num tempo em que não se pode continuar a viver na ingenuidade de recém-nascidos. Nos aproximamos da morte total do que jamais estiveram nossos antepassados. Todas as espécies vivas estão ameaçadas pela violência do modo atual de viver, produzir, consumir e descartar. Consumir a existência alheia tornou-se a forma de vida de todos os humanos, da alimentação ao vestuário, do lazer ao medicamento, da cosmética à guerra. Tudo passa por tirar a vida dos animais, ou privá-los de seu bem-estar específico. Desde o Código de Hammurabi a vida das bestas tinha valor por ser objeto de troca. Hoje, quatro mil anos mais tarde, a vida de qualquer ser vivo, incluindo os humanos, só tem valor se for de interesse comercial (FELIPE, 2009).

Uma ética centrada na vida considera moralmente relevantes todos os seres vivos, e exige que, na hora de decidir como temos de atuar, tenhamos em conta os impactos de nossas ações sobre todo o ser vivo afetado por elas (ELLIOT, 2004).

Os países desenvolvidos esquecem que desigualdades causam danos ambientais em larga escala. Querem ajudar, por meio da criação de fundações e de doações em dinheiro para ações em países pobres, contudo não atingem o consumismo, o comércio injusto, as barreiras protecionistas de seus mercados e a especulação financeira, que são inerentes a dinâmica do capitalismo global contemporâneo. Como exemplo, algumas organizações situadas em países desenvolvidos doam milhões de redes anti-mosquitos para famílias africanas evitarem o contágio da população pela malária, contudo, estas as utilizam como redes de pesca para auxiliar na busca diária de ter o que comer, afinal não tem garantida sua segurança alimentar (criando outro problema ambiental ao afetarem a população de peixes, poluírem rios e mananciais com as redes envenenadas). Podemos ver claramente o quanto as dimensões temporal, territorial, social e Ecológica da Justiça Socioecológica estão interligadas.

As desigualdades de renda no mundo aumentaram consideravelmente. Piketty (2014) aborda que:

[...] a evolução dinâmica de uma economia de mercado e de propriedade privada, deixada a sua própria sorte, contem forças de convergência importantes, ligadas sobretudo a difusão do conhecimento e das qualificações, mas também forças de divergências vigorosas e potencialmente ameaçadoras para nossas sociedades 
democráticas e para os valores de Justiça social sobre os quais elas se fundem (PIKETTY, 2014, p.555)

A mesma evolução da economia de mercado deixada à própria sorte é um ponto chave para entendermos como as dimensões da Justiça Socioecológica são deixadas de lado em favor da visão puramente economicista de um desenvolvimento que vem para explorar indivíduos e outras espécies. Trata-se de um modelo de desenvolvimento que de acordo com Muller (2014) concentrou no final do ano de 2014, nas mãos das 67 pessoas mais ricas, tanto dinheiro quanto os 3,5 bilhões de habitantes mais pobres do planeta.

Segundo Jacobi (2003) a dinâmica socioambiental que caracteriza as sociedades atuais, revela que o impacto dos seres humanos sobre o meio ambiente tem consequências cada vez mais complexas, tanto em termos quantitativos quanto qualitativos. $\mathrm{O}$ atual cenário se dá, também, por conta de evidente contradição: enquanto somos parte dela e precisamos da natureza para sobrevivência, estamos nos desconectando dela. Coisificando aquilo que acreditamos estar subjugado a nós. A reversão do caminho será possível buscando a reconexão. É preciso compreender quais as consequências de nossos atos (CASTRO, 2014).

O que fica claro é a responsabilidade dos seres humanos com a atual situação planetária, com os problemas criados. Apesar das recorrentes conferências globais com a intenção de firmar planos e compromissos que reduzam a emissão de poluentes a médio e longo prazo, pouco se tem avançado. Esses encontros têm servido muito mais para apresentar recomendações do que efetivamente mostrar soluções aplicadas - ou que serão implantas efetivamente (JATOBA et al., 2009). A necessidade urgente de preservar nosso planeta passa por quebras de paradigmas, adoção de políticas que utilizem verdadeiramente o poder e a gestão para o bem comum. Quando setor público e população caminham juntos, torna-se mais fácil adotar mudanças de valores na sociedade, aplicar a Justiça Socioecológica e situar o ser humano não como o centro, mas como parte integrante de um todo, respeitando verdadeiramente a própria casa e existência.

\section{A experiência francesa do Accueil Paysan e o projeto Acolhida na Colônia}

A associação Accueil Paysan originou-se em 1987, resultado de uma longa reflexão dos agricultores da região de Rhône-Alpes (França), que buscavam desenvolver a produção agrícola integrada, que respeitasse as pessoas e seu ambiente familiar, proporcionando o desenvolvimento harmonioso do território (ACCUEIL PAYSAN, 2015). 
Cabe ressaltar que o Accueil Paysan era uma forma de posicionar-se como uma alternativa diferenciada do modelo dominante de desenvolvimento agrícola (intensivo) que significa muitas vezes a degradação dos recursos naturais. A intenção era apoiar a agricultura familiar, por meio da diversificação de cultivos, elaboração de produtos com qualidade, fabricados de acordo com o ambiente.

Seria uma forma de ajudar os agricultores a manter suas terras, não utilizar práticas agrícolas poluentes e evitar a desertificação das zonas rurais. Estes foram alguns dos motivos que impulsionaram o desenvolvimento da associação, fundada também sob bases de educação popular (ACCUEIL PAYSAN, 2015).

Originada e integrada ao modelo Francês Accueil Paysan, atuante em 18 países compreendendo a Europa, América Latina, África e Ásia, a Acolhida na Colônia é uma associação de agricultores familiares que compartilham o objetivo de valorizar o modo de vida no campo com apoio do agroturismo. Criada no Brasil em 1998, a Associação iniciou em 1999 o projeto piloto no território das Encostas da Serra Geral, ao sudeste de Santa Catarina, incluindo os municípios de Rancho Queimado, Anitápolis, Santa Rosa de Lima, Gravatal e Grão-Pará (GUZZATTI, 2003).

A instituição foi criada para desenvolver o agroturismo, modalidade de turismo realizada no espaço rural, onde agricultores familiares organizados estão dispostos a compartilhar seu modo de vida, patrimônio cultural e natural, mantendo suas atividades econômicas, oferecendo produtos e serviços de qualidade, valorizando e respeitando o ambiente e a cultura local e proporcionando bemestar aos envolvidos (GUZZATI, SAMPAIO, CORIOLANO, 2013).

Também se desenvolveram estratégias e ações para que seus princípios fossem respeitados pelos associados. Entre as principais ações estão programas de formação e intercâmbio (cursos, palestras, seminários, visitas técnicas nacionais e internacionais, dentre outros) aos agricultores; assessoria técnica nas propriedades rurais; desenvolvimento de projetos especiais como o Roda d'Água (resgate e implantação de tecnologias de energia renovável); desenvolvimento de roteiros de turismo pedagógico para promover a educação ambiental; desenvolvimento de circuitos de ciclo turismo, dentre outras ações (GUZZATI, SAMPAIO, CORIOLANO, 2013).

A Acolhida na Colônia conta atualmente com 73 propriedades distribuídas em 18 municípios catarinenses compreendendo cinco regiões definidas pela Associação: Encostas da Serra Geral (Anitápolis, Gravatal, Imbituba, Rancho Queimado, Santa Rosa de Lima, São Bonifácio); Ibirama (Apiúna, Presidente Getúlio, Presidente Nereu, Vitor Meirelles e Witmarsum); Ituporanga (Aurora e Atalanta); Vale dos Imigrantes (Rio do Sul, Agrolândia, Agronômica) e Serra Catarinense (São Joaquim e Urubici) (ACOLHIDA NA COLÔNIA, 2015). 


\section{O projeto Acolhida na Colônia e as dimensões da Justiça Socioecológica}

A regional Ituporanga da Acolhida na Colônia conta atualmente com seis propriedades em Aurora e quatro propriedades em Atalanta (ACOLHIDA, 2015).

Do ponto de vista da dimensão social da Justiça Socioecológica, além da melhoria de renda para as famílias proporcionada após a participação no projeto, que foi citada por cinco entre as seis propriedades pesquisadas (Ipê, Imbuia, Manacá, Cedro e Canela), houve um grande reconhecimento em relação às melhorias na alimentação com igual número de citações espontâneas. Hoje, na maioria das propriedades que trabalham com o agroturismo a alimentação é assegurada quantitativa e qualitativamente. Isto se deve a dois aspectos em especial. Primeiro porque as normas da Associação são bastante claras com relação ao procedimento do alimento oferecido ao turista, exigindo que pelo menos $50 \%$ seja proveniente da propriedade. Da mesma forma, os princípios prezam pela qualidade do que é oferecido, dando preferência aos alimentos de origem orgânica. Segundo, porque a partir do momento que esse aspecto foi trabalhado com os agricultores, a prática de produção de alimentos e alguns hábitos alimentares foram também incorporados pelas famílias, como por exemplo, a introdução de saladas e frutas nas refeições e a redução da gordura no preparo dos alimentos.

Embora não seja o caso de todos os agricultores envolvidos com o agroturismo, percebe-se que os princípios estabelecidos pela Associação colaboraram com a retomada destas práticas reforçando a importância da produção para o consumo, a diversificação dos produtos e a substituição de técnicas convencionais (uso de agrotóxicos) por outras voltadas à produção orgânica.

A valorização social foi reconhecida pelo conjunto dos entrevistados. O agroturismo também colabora para outros aspectos relativos à qualidade de vida dos agricultores, entre eles a melhoria de questões ambientais das propriedades, aumento da autoestima dos agricultores (também relacionando ao reconhecimento social), além dos benefícios à saúde física e mental.

A propriedade Ingá recentemente mudou de mãos. O atual proprietário acredita que não obtém ganhos ao participar no Acolhida, principalmente pelos produtos fabricados e canais de distribuição envolverem formas não dependentes da visitação de turistas. Ele afirma permanecer na associação em apoio à causa, e assim como as propriedades Ipê, Imbuia, Manacá, Cedro e Canela revela que o reconhecimento social é um grande diferenciador.

Outro aspecto observado diz respeito à divisão do trabalho. No geral, os homens se encarregam das atividades agrícolas e da organização do ambiente externo. As mulheres, além de terem uma participação variável nos serviços gerais, se envolvem de forma mais direta com a atividade turística, desde sua organização até os serviços internos (arrumação, organização dos 
ambientes, alimentação) também na confecção de artesanatos. Há uma valorização do papel da mulher agricultora familiar na atividade turística.

Ocorre uma flexibilização adaptativa da propriedade para responder, simultaneamente, a duas funções distintas, a de meio de produção da agricultura e do turismo. Percebe-se, entretanto, uma tendência a concentrar esforços sobre a função que aporta maior renda. Por isso, mesmo defendendo a diversificação da propriedade, os agricultores, em vários depoimentos, apontam como estratégia para o rearranjo produtivo, priorizar algumas atividades em detrimento de outras. Porém, se por um lado a inserção do turismo nas propriedades gera novos esforços, pode também significar a redução de outros. Percebe-se que o espaço da propriedade agrícola vem se organizando segundo a expressividade de cada setor sobre ele, ou seja, nas propriedades em que o turismo se sobressai, o espaço se adapta para atendê-lo e naquelas onde a agricultura continua sendo a atividade principal, os investimentos e a atenção voltada à atividade turística se expressam de forma menos evidente. Embora a especialização tenha se mostrado uma tendência, é preciso chamar a atenção para o fato de que as atividades agrícolas não devem perder importância, apenas mudar de função quando a propriedade se insere no agroturismo.

Com relação à dimensão territorial, a ideia de que o agroturismo é uma atividade complementar à agricultura e que deve ser desenvolvido de forma associativa e para o desenvolvimento do território vem sendo buscada pela Acolhida, mas surgem algumas contradições entre a ideia e a prática. A iniciar pela originalidade do espaço, nas propriedades em que o turismo se sobressai, os investimentos podem inclusive afetar a questão ambiental da propriedade, com construções suprimindo áreas que deveriam estar preservadas (casos das propriedades Ingá e Cedro).

Outra contradição diz respeito ao trabalho associativo e em rede, onde a diversificação dos serviços em alguns empreendimentos associados comprometeu o trabalho de complementaridade incentivado na concepção de circuito. Hoje o que se percebe é que os turistas passam a maior parte do tempo no empreendimento onde visitam e/ou se hospedam, sem conhecer a rede local. As contradições evidenciam que as expectativas dos associados estão indo além do que foi estabelecido no âmbito da Associação e que o turismo está deixando a agricultura em um segundo plano. A complementaridade entre as propriedades e entre atividades através do associativismo foi uma necessidade no início do processo e a situação hoje vem se modificando.

A dimensão ecológica dos empreendimentos pode ser observada com muita clareza, mas existem ressalvas. As propriedades Ingá e Cedro apresentam detalhes nas construções, como proximidade excessiva de ribeirões com supressão da mata ciliar. A Acolhida na Colônia em seu âmbito geral possui uma posição claramente contrária à utilização de agrotóxicos, ao reflorestamento com espécies exóticas, ao desmatamento, da exploração do subsolo assim como a construção de 
Pequenas Centrais Hidrelétricas. Todas as propriedades aboliram a utilização de agrotóxicos, o desmatamento deixou de ser realizado com a adoção de uma nova consciência, que valora aquele espaço e os seres que ali habitam com maior equidade. Não há exploração do subsolo. O aproveitamento das forças de uma queda d’água são utilizadas para um moinho na propriedade Cedro, mas sem grandes impactos, uma vez que está plenamente integrada ao ambiente a mais de meio século, sem interferir no curso normal do ribeirão. O reflorestamento com espécies exóticas ocorre em duas outras propriedades. A propriedade Manacá possui 50\% a mais de terras com reflorestamento de espécies exóticas do que mantém em mata nativa, enquanto a propriedade Canela possui igual quantidade de reflorestamento e mata nativa preservada. A tendência apontada em todas as propriedades é a substituição gradual dos reflorestamentos de espécies exóticas por espécies do território.

A consciência quanto aos seres vivos, não humanos, teve uma grande alteração com a participação das propriedades no Acolhida na Colônia, tanto as espécies vegetais como animais (e nestas incluem-se as domésticas e nativas do território) passaram a dispor de uma melhor compreensão. Embora os animais domesticados continuem tendo papel econômico, de dominação, a interação com eles ganhou muito em respeito a suas características biológicas. Com relação aos animais e à mata nativa, o princípio da não interferência e da preservação é essencialmente buscado, com destaque para as propriedades Imbuia e Ipê, embora por se tratarem de pequenas propriedades de agricultura familiar, as interferências continuam a existir direta ou indiretamente. Nas duas propriedades o respeito ao valor intrínseco dos seres possui maior relevância, com uma ética muito mais centrada na vida e não no valor instrumental dos seres em benefício dos humanos.

Por fim, a dimensão temporal, o preservar para as gerações futuras, é observada em todas as propriedades. Esta preocupação é observada não de maneira conservacionista utilitarista, para uso futuro, mas de maneira preservacionista, assegurando a conservação da biodiversidade nas propriedades, e o respeito a cultura dos agricultores familiares em seu território.

Cabe ressaltar ao longo do tempo a evolução das diferentes pedagogias envolvidas na agricultura. No início a pedagogia agrícola tradicional, baseada no conflito com o ambiente natural, uma agricultura de técnicas ditas rudimentares, como a exploração da terra por meio de equipamentos manuais e das ditas coivaras (queimadas). Após a Segunda Guerra Mundial, uma pedagogia agrícola que se tornou convencional, biotecnológica, de domínio da natureza por meio de adubos e defensivos químicos, com maquinaria avançada, culminando nas "melhorias genéticas”. Esta segunda pedagogia continua sendo amplamente utilizada. E uma terceira pedagogia, esta Agroecológica, e associada à Acolhida na Colônia. 
Segundo Martins (2014) a agroecologia propõe uma relação homem-natureza que respeite minimamente os tempos e as lógicas naturais e uma relação homem x homem que supere a opressão e a marginalização, além de uma economia que se baseie muito mais na satisfação das necessidades individuais e sociais do que no lucro.

Projetos voltados à educação de crianças e adultos por meio da observação do ambiente e do compartilhamento de conhecimentos dos agricultores familiares são desenvolvidos com grande foco sobre a preservação. Em todas as propriedades existe essa consciência, em especial a propriedade Cedro chamou a atenção pelo conhecimento histórico transmitido por seu proprietário, pela evolução nos cuidados com a questão ambiental, e pelo respeito pelos conhecimentos tradicionais e a busca da transmissão destes para as futuras gerações.

\section{Considerações finais}

Este estudo teve como objetivo principal analisar o projeto Acolhida na Colônia em relação às dimensões da Justiça Socioecológica. A instituição foi criada para desenvolver o agroturismo, modalidade de turismo desenvolvida no espaço rural, onde agricultores familiares organizados estão dispostos a compartilhar seu modo de vida, patrimônio cultural e natural, mantendo suas atividades econômicas, oferecendo produtos e serviços de qualidade, valorizando e respeitando o ambiente e a cultura local e proporcionando bem-estar aos envolvidos. O agroturismo aparece como uma alternativa para o desenvolvimento territorial capaz de envolver as dimensões espaciais, culturais, sociais, econômicas e ecológicas.

O projeto Acolhida na Colônia possui algumas contradições entre a sua ideia inicial e a prática. A ideia inicial do projeto é totalmente aderente aos princípios da Justiça Socioecológica, contudo em sua prática alguns pontos se sobressaem e precisam ser adequados pois, atualmente, afetam as dimensões territorial e ecológica. Há uma mudança na originalidade do espaço, nas propriedades em que o turismo se sobressai muitos investimentos com construções acabam suprimindo áreas que deveriam estar preservadas (casos das propriedades Ingá e Cedro). Outra contradição diz respeito ao trabalho associativo e em rede, onde a diversificação dos serviços em alguns empreendimentos associados comprometeu o trabalho de complementaridade incentivado na concepção de circuito. Hoje o que se percebe é que os turistas passam a maior parte do tempo no empreendimento onde visitam e/ou se hospedam, sem conhecer a rede local.

Observou-se com relação as dimensões da Justiça Socioecológica que a maneira independente como o projeto Acolhida foi criado e desenvolvido reforça a adoção de modernos princípios de 
governança capaz de entrelaçar a sociedade, com participação ativa de grupos sociais vulneráveis (caso dos agricultores familiares) nos diversos territórios em que atua. A participação na instituição foi capaz de gerar benefícios não só com relação a geração de renda, mas melhorias na saúde (em especial na alimentação), e no reconhecimento social e valorização do papel do agricultor familiar. O reconhecimento social estimula a manutenção das pessoas no campo e consequentemente de sua cultura. Com relação à dimensão ecológica, as propriedades demonstram grande evolução desde o início de sua participação no projeto. Ainda existe um caminho de ajustes a serem realizados, mas são claras as diferenças entre os participantes da Acolhida frente aos demais agricultores familiares, em termos de educação e consciência ambiental.

Por fim a dimensão temporal do projeto ficou evidente em todas as propriedades pela preocupação da preservação tanto ambiental quanto cultural e a transmissão destas para as próximas gerações, seja através das visitas dos turistas, seja por meio dos projetos pedagógicos e da própria maneira como as propriedades mudaram seus modelos de produção tradicionais ou convencionais para a agroecologia.

Desta maneira, concluímos que o projeto Acolhida na Colônia, mesmo com as ressalvas apontadas na pesquisa, caminha no sentido da Justiça Sócio- Ecológica. 


\section{Referências}

ACCUEIL PAYSAN. Qui sommes-nous. Disponível em:

<http://www.accueilpaysan.com/Pages/presentation.html> Acesso em: 03 de novembro de 2015.

ACOLHIDA NA COLÔNIA, 2015. Disponível em: <http://www.acolhida.com.br/>. Acessos entre 15 de outubro de 2015 e 31 de dezembro de 2016.

ALIER, J. M.. O Ecologismo dos Pobres. Contexto, São Paulo: 2007.

BAXTER, B. A Theory of Ecological Justice. New York: Routledge, 2005

BBC: Próximos dois anos podem ser os mais quentes já registrados, diz agência britânica. Brasil, 14 set. 2015. Disponível em:

http://www.bbc.com/portuguese/noticias/2015/09/150914_mudancas_climaticas_rm>. Acesso em: 09 fev. 2016.

CASTRO, E. V. de; DANOWSKI, D. Diálogos sobre o fim do mundo. Entrevista concedida a Eliane Brum. Diário El País, Edição Brasil, 24 de setembro de 2014.

ELLIOT, R. "La ética ambiental" pp. 391-404 in Singer, Peter (Ed.) Compendio de ética. Madrid: Alianza Editorial, 2004.

FELIPE, S. T. Antropocentrismo, sencientismo e biocentrismo: Perspectivas éticas abolicionistas, bem-estaristas e conservadoras e o estatuto dos animais não humanos. Revista Páginas de Filosofia. V.1. n.1, jan-jul/2009.

GUZZATTI, T. C. O agroturismo como instrumento de desenvolvimento rural; Sistematização e análise das estratégias utilizadas para a implantação de um programa de agroturismo nas encostas da Serra Geral Catarinense. Dissertação de Mestrado em Engenharia de Produção - Universidade Federal de Santa Catarina, Florianópolis, 2003

GUZZATTI, T.C. Agroturismo em Santa Catarina: Acolhida na Colônia. São Paulo: [s.n.], 2010.

GUZZATTI, T.C.; Sampaio, C.A.C.; Coriolano, L.N.M.T. Turismo de base comunitária em territórios rurais: caso da Associação de Agroturismo Acolhida na Colônia (SC). Revista Brasileira de Ecoturismo, São Paulo, v.6, n.1, jan/abr-2013, pp.93-106.

JACOBI, P. Educação Ambiental, Cidadania e Sustentabilidade. Cadernos de Pesquisa. n. 118, p. 189-205, 2003.

JATOBA, S. U. da S. et al. Ecologismo, ambientalismo e ecologia política: diferentes visões de sustentabilidade e do território. Soc. Estado [online]. 2009, vol.24, n.1, pp 47-87.

KOPNINA, H. Environmental justice and biospheric egalitarianism: reflecting on normative philosophical view of human-nature relationship. Earth Perspectives 2014, 1:8 doi:10.1186/21946434-1-8. http://www.earth-perspectives.com/cotent/1/1/8\#. 
MARTINS, J. Pedagogias Agrícolas: Continuidades e rupturas. Uma abordagem educacional sobre transições agroecológicas. 2013. 209f. Tese (Programa de Pós Graduação em Educação), UFSC, Florianópolis, 2013.

MULLER, A. Os verdadeiros donos do mundo. Revista Superinteressante. Edição 341.Editora Abril, São Paulo, 2014, P 32-41.

PIKETTY, T. O Capital do século XXI. A contradição central do Capitalismo. Intrínseca. Rio de Janeiro, 2013, p. 555-561.

SAMPIERI, R. H. et al. Metodologia de Pesquisa. 3. ed. São Paulo: Mc-graw-hill, 2006.

STEFFAN, H. D. Novo guia para pesquisa científica. Blumenau: Furb, 1999.

SINGER, P. Ética prática.2.ed. São Paulo: Martins Fontes, 1998.

ZUINDEAU, B. Territorial Equity and Sustainable Development, in Environmental Values 16 (2007): 253-268, The White Horse Press.

Artigo recebido em 17/01/2018. Aceito para publicação em 25/09/2018. 